\title{
Fructose-1,6-bisphosphate aldolase encoded by a core gene of Mycoplasma hyopneumoniae contributes to host cell adhesion
}

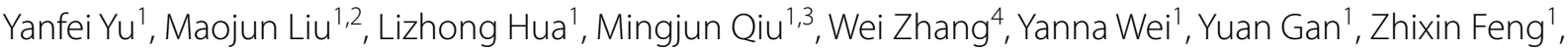 \\ Guoqing Shao ${ }^{1}$ and Qiyan Xiong ${ }^{1 *}$
}

\begin{abstract}
Mycoplasma hyopneumoniae is an important respiratory pathogen that causes great economic losses to the pig industry worldwide. Although some putative virulence factors have been reported, pathogenesis remains poorly understood. Herein, we evaluated the relative abundance of proteins in virulent 168 (F107) and attenuated 168L (F380) M. hyopneumoniae strains to identify virulence-associated factors by two-dimensional electrophoresis (2-DE). Seven proteins were found to be $\geq 1.5$-fold more abundant in 168 , and protein-protein interaction network analysis revealed that all seven interact with putative virulence factors. Unexpectedly, six of these virulence-associated proteins are encoded by core rather than accessory genomic elements. The most differentially abundant of the seven, fructose-1,6-bisphosphate aldolase (FBA), was successfully cloned, expressed and purified. Flow cytometry demonstrated the surface localisation of FBA, recombinant FBA ( $r F B A$ ) mediated adhesion to swine tracheal epithelial cells (STEC), and anti-rFBA sera decreased adherence to STEC. Surface plasmon resonance showed that rFBA bound to fibronectin with a moderately strong $K_{D}$ of $469 \mathrm{nM}$. The results demonstrate that core gene expression contributes to adhesion and virulence in M. hyopneumoniae, and FBA moonlights as an important adhesin, mediating binding to host cells via fibronectin.
\end{abstract}

\section{Introduction}

Mycoplasma hyopneumoniae is the etiological agent of porcine enzootic pneumonia, one of the most damaging respiratory diseases affecting pig farming. Despite low direct mortality, M. hyopneumoniae can lower the feed conversion efficiency and reduce the growth rate, resulting in large economic losses.

The M. hyopneumoniae pathogen colonises and destroys the epithelial surfaces of the respiratory tract [1], and adhesion to the respiratory epithelium is the first and most important step in infection [2,3].

${ }^{*}$ Correspondence: qiyanxiongnj@163.com

${ }^{1}$ Key Laboratory of Veterinary Biological Engineering and Technology of Ministry of Agriculture, Institute of Veterinary Medicine, Jiangsu Academy of Agricultural Sciences, Nanjing, China

Full list of author information is available at the end of the article
Several proteins are involved in adhesion, including P97, the first adhesin to be identified in this species, which binds to the cilia of respiratory epithelial cells via its C-terminal R1 domain [4]. Other adhesion factors, such as P102 [5, 6], P159 [7], P146 [8], P216 [9], P116 [10], Mhp271 [11], Mhp683 [12], Mhp107 [13] and so on have since been reported. Not only these adhesins, but also multifunctional cytosolic proteins "moonlighting" at the cell surface contribute to M. hyopneumoniae adhesion [14]. They include the following: MHJ_0125, a glutamyl aminopeptidase that moonlights as an adhesin on the surface of M. hyopneumoniae [15]; MHJ_0461, a leucine aminopeptidase which binds to heparin, plasminogen and foreign DNA and functions as an accessory adhesin [16]; and L-lactate dehydrogenase, an immunogenic cytoplasmic protein involved in the glycolytic process but also present at 
the cell surface with adhesin functions [17]. Glyceraldehyde 3-phosphate dehydrogenase (MHJ_0031) has also been identified as a putative moonlighting protein because it was predicted within a putative heparinbinding region [18]. Finally, elongation factor thermo unstable (EF-Tu), functions as an adhesin on the surface of M. hyopneumoniae by binding to multiple host proteins $[19,20]$. However, despite these findings, the exact mechanisms responsible for pathogenesis and potential virulence factors in M. hyopneumoniae remain poorly understood [21].

Although infection by M. hyopneumoniae is highly prevalent (ranging between 38 and 100\%) in almost all areas of pig production worldwide, there are discrepancies in terms of pathogenicity among isolates of $M$. hyopneumoniae. Comparative proteomics research, which offers a systematic analysis, can reveal novel putative virulence factors between bacterial strains in which virulence differs. For example, the available proteome map of $M$. hyopneumoniae strain 7448 served as a reference for comparative analysis of differentially virulent $M$. hyopneumoniae strains [22]. A subsequent proteomic comparison of $M$. hyopneumoniae pathogenic strain 232 and avirulent strain J revealed 11 differentially abundant proteins [23]. However, differences are evident among the genome sequences of $M$. hyopneumoniae strains. For example, the size of the genome ranges from 892758 bp (strain 232, AE017332) to $964503 \mathrm{bp}$ (strain KM014, CP022714). Furthermore, differences are magnified after translation into proteins, due to variation in regulation and modification at both RNA and protein levels. Thus, the results obtained from comparative proteomics analyses of different sources of bacterial strains can be confusing, preventing the ability to focus on the most critical and common factors [24]. Subjecting strains with a consistent genomic background but differences in virulence to comparative proteomics analysis is one potential solution. To this end, we obtained the attenuated M. hyopneumoniae strain 168L (F380) from continuous passage of pathogenic strain 168 (F107) in cell-free medium [25]. Herein, we performed comparative proteomic analysis on these strains and identified a number of putative virulence-associated proteins. We demonstrate how pan-genome dynamics, linked to conserved and transposable elements, may help in the characterisation of virulence factors identified via comparative proteomics analysis. The findings highlight novel virulence-associated factors and the biological versatility of known proteins, leading to a more complete understanding of the complex physiological and infectious processes operating in $M$. hyopneumoniae.

\section{Materials and methods}

\section{Ethics statement}

All animal experiments were approved by the Committee on the Ethics of Animal Experiments and performed in Jiangsu Academy of Agricultural Sciences (License No. SYXK (Su) 2015-0019). The experimental procedures conformed to the guidelines of Animal Regulations of the Jiangsu Province (Government Decree No. 45) in accordance with international law.

\section{Bacterial strains and growth conditions}

Mycoplasma hyopneumoniae strain 168 was isolated in Gansu Province, China, from a pig exhibiting typical characteristics of mycoplasmal pneumonia of swine (MPS) [26]. This field strain was cultured in KM2 cellfree liquid medium (a modified Friis medium) containing $20 \%$ (v/v) swine serum at $37^{\circ} \mathrm{C}$, and was gradually attenuated by continuous passage to the $380^{\text {th }}$ passage, yielding strain168L [25].

\section{Evaluation of virulence in M. hyopneumoniae strains 168 and $168 \mathrm{~L}$}

Nine non-immunised cross-bred (Xiaomeishan $\times$ Landrace) 50-day-old snatch-farrowed, porcine-colostrumdeprived (SF-pCD) piglets were raised according to the methods described by Huang et al. [27, 28]. All nine piglets used to evaluate the virulence of $M$. hyopneumoniae strains 168 and 168L were free of sera IgG antibody recognising classical swine fever virus (CSFV Antibody Test Kit, IDDEXX Laboratories, USA), porcine reproductive and respiratory syndrome virus (PRRSV Antibody Test Kit, IDEXX Laboratories, USA), porcine pseudorabies virus (PRV Antibody Test Kit, IDEXX Laboratories, USA), porcine circovirus type 2 (PCV2 Antibody Test Kit, JBT, South Korea), and M. hyopneumoniae (M. hyopneumoniae Antibody Test Kit, IDEXX Laboratories, USA). They were also free of secretory IgA antibody recognising $M$. hyopneumoniae [29], and antigen of PCV2 [30] and M. hyopneumoniae [29]. The piglets were divided randomly into three groups (three piglets/ group) and raised in three separate rooms. The piglets were intratracheally challenged with $5 \mathrm{~mL}$ of a $10^{8}$ colour change unit $(\mathrm{CCU}) / \mathrm{mL}$ culture of strains 168 or 168L (or KM2 medium as a negative control). The piglets were observed daily for clinical signs of pneumonia, such as coughing and asthma. All animals were euthanised at 28 days after challenge, and lung lesions were scored using the rule of 28 method [31]. A value was assigned to seven pulmonary lobes based on the average extent of mycoplasmal lesions. Each pulmonary lobe was scored for severity of mycoplasmal lesions ranging from 0 to 4 $(0=$ absence of lobular pneumonia; $1=1-25 \%$ lesions; $2=26-50 \%$ lesions; $3=51-75 \%$ lesions; $4=76-100 \%$ 
lesions). For each animal, the sum of seven pulmonary lobes ranged from 0 to 28 . All data were analysed by analysis of variance (ANOVA) using SPSS 20.0 software, and differences were considered significant at $p \leq 0.05$.

\section{Protein extraction and two-dimensional electrophoresis (2-DE)}

Cultures of strains 168 and 168L were harvested by centrifugation at $16000 \times g$ for $20 \mathrm{~min}$ at $4{ }^{\circ} \mathrm{C}$ at the late exponential phase of growth. Pellets were washed three times with $10 \mathrm{mM}$ TRIS- $\mathrm{HCl}(\mathrm{pH} 7.4)$ and resuspended in protein extract consisting of $1.52 \mathrm{~g}$ thiourea, $4.2 \mathrm{~g}$ urea, 0.4 g CHAPS, $200 \mu \mathrm{L}$ amphoteric electrolyte, $61.6 \mathrm{mg}$ dithiothreitol (DTT; all Bio-Rad), and protease inhibitor (Merck) dissolved in $10 \mathrm{~mL}$ ultrapure water. After vortexing and centrifugation, total protein in the supernatant was subjected to cleanup with a ReadyPrep 2-D cleanup kit (Bio-Rad). Purified proteins were redissolved in $350 \mu \mathrm{L}$ rehydration solution (7 M urea, $2 \mathrm{M}$ thiourea, $0.001 \%$ bromophenol blue; Bio-Rad) and centrifuged to remove insoluble components. Samples were finally loaded onto a $17 \mathrm{~cm}$ strip (pH 3-10; Bio- Rad) and isoelectric focusing (IEF) was carried out at $20^{\circ} \mathrm{C}$ by positively rehydrating at $50 \mathrm{~V}$ for $12 \mathrm{~h}$, increasing slowly to $250 \mathrm{~V}$ for $1 \mathrm{~h}$, rapidly to $1000 \mathrm{~V}$ for $1 \mathrm{~h}, 10000 \mathrm{~V}$ for $3 \mathrm{~h}$, rapidly to $10000 \mathrm{~V}$ to a total of $90000 \mathrm{Vh}$, then rapidly to $500 \mathrm{~V}$. Sodium dodecyl sulphate-polyacrylamide gel electrophoresis (SDS-PAGE) was then performed according to a previous protocol [24].

\section{Image analysis, MALDI-TOF-MS/MALDI-TOF-TOF-MS, and database searching}

After Coomassie blue staining of the SDS-PAGE gel, the detected protein spots from each gel were matched automatically using PDQuest V8.0 software with additional visual analysis. The intensity of individual spot was normalised relative to the total valid spot intensity for each gel. Protein expression levels were calculated as the foldchange. Only spots for which the abundance in strain 168 was $\geq 1.5$-fold higher than in strain 168L (Student's $t$ test $\geq 0.05$ ) were excised from the 2-DE gel and subjected to matrix-assisted laser desorption/ionisation time-of-flight mass spectrometry (MALDI-TOF-MS/MALDI-TOFTOF-MS) analysis. Peptide mass fingerprinting data were analysed using the MASCOT server. Peptides with a rank of 1 in the MASCOT search were considered significant and used for the combined peptide score.

\section{Protein-protein interaction analysis}

To investigate the contribution of the identified differentially abundant proteins to the virulence of $M$. hyopneumoniae, we summarised the putative virulence factors reported in previously published papers [3, 21]. The
STRING database was used to generate protein-protein interactions between known virulence factors and the novel differentially abundant proteins identified in this study. Only interactions with a confidence score of at least 0.4 were considered for analysis. The protein-protein interaction network was visualised using Cytoscape (3.5.1).

\section{Core genome analysis}

The gene profile (content) of a pan-genome, defined as the entire genomic repertoire of a given species, can be divided into core (shared by all genomes), dispensable, and strain-/isolate-specific genes [32, 33]. The available genomes of nine different $M$. hyopneumoniae strains were downloaded from the NCBI website for core genome analysis [32]. The accession numbers are as follows: strain J, AE017243; strain 168, CP002274; strain 168L, CP003131; strain 232, AE017332; strain 7422, PRJNA47327; strain 7448, AE017244; strain 11, MWWN00000000; strain KM014, CP022714; strain TB1, Scaffold. All genome data are available from NCBI FTP. A pan-genome computation was performed using PGAP v1.2.1, which performs the analysis according to the Heaps low pan-genome models for these genomes. After the input files were built using the Converter_NCBINewFormatData.pl script within PGAP, the PGAP.pl script of PGAP was executed using the Gene Family (GF) method to build a pan-genome profile [34]. Graphs were drawn using an in-house R script.

\section{Preparation of polyclonal antibody recognising recombinant FBA ( $\mathrm{FBB}$ )}

The full-length $f b a$ gene (MHP168_014) was cloned into the $\mathrm{pET}-28 \mathrm{a}(+)$ vector by site-directed mutation and overlap extension (SOE-PCR) due to the existence of rare codons, and rFBA was produced in Escherichia coli BL21 (DE3) and purified by $\mathrm{Ni}$-chelating chromatography as described in a previous study [19]. A polyclonal antibody was raised against rFBA by subcutaneously immunising 1-month-old New Zealand white rabbits. Each rabbit was immunised three times with $1 \mathrm{mg}$ of rFBA emulsified in Freund's adjuvant (Sigma, USA) at 2-week intervals. Sera were collected at 1 week after the third immunisation.

\section{Western blot validation of comparative proteomics analysis}

Equal amounts $(40 \mu \mathrm{g})$ of each protein sample were separated on a $12 \%$ SDS-PAGE gel, and proteins were electrophoretically transferred onto polyvinylidene fluoride (PVDF) membranes (Millipore, Germany) and developed with Ponceau-S as the loading control. After blocking with TBST buffer comprising $20 \mathrm{mM}$ TRIS-HCl (pH 7.6), $150 \mathrm{mM} \mathrm{NaCl}$ and $0.1 \%$ Tween-20 containing 
5\% skimmed milk, membranes were probed with antirFBA antibody (1:2000 dilution). Horseradish peroxidase (HRP)-conjugated secondary antibody (1:10 000 dilution) was used for final identification. ImageJ software was used to calculate the optical density (OD) of the corresponding bands. The OD of FBA from different samples was normalised to that of the Ponceau-S-stained membrane. The abundance of FBA in $M$. hyopneumoniae strain $168 \mathrm{~L}$ is expressed as the percentage of that in $M$. hyopneumoniae strain 168 . Three replicates were subjected to statistical analysis by SPSS 20.0.

\section{Detection of surface-exposed FBA by flow cytometry}

To investigate whether FBA is present on the surface of M. hyopneumoniae strain 168, and to probe FBA surface content differences between 168 and 168L, flow cytometry was performed. In brief, $M$. hyopneumoniae strains 168 and $168 \mathrm{~L}$ (each $1 \times 10^{8} \mathrm{CCU} / \mathrm{mL}$ ) were incubated with anti-rFBA serum at a 1:100 dilution (1:100 diluted preimmune serum was used as a negative control). $M$. hyopneumoniae cells were then stained with fluorescein isothiocyanate (FITC)-conjugated anti-IgG and the fluorescence intensity was measured using a BD Accuri C6 flow cytometer as described previously [35]. The mean fluorescence intensity (MFI) of M. hyopneumoniae incubated with anti-rFBA serum is expressed as the foldchange relative to the corresponding strain incubated with preimmune serum. The assay was performed in triplicate, and data were analysed using Student's $t$ tests in SPSS 20.0. For all tests, $p \leq 0.05$ was considered statistically significant.

Adherence of rFBA to swine tracheal epithelial cells (STEC) To investigate the ability of rFBA to promote adherence to STEC, indirect immunofluorescence assays were performed. STEC were grown to confluence in 24-well plates with RPMI-1640 medium (Thermo Fisher Scientific, USA) supplemented with $10 \%(\mathrm{v} / \mathrm{v})$ fetal bovine serum (Gibco, USA). After incubation with $100 \mu \mathrm{g}$ of purified rFBA, the cells were washed three times with phosphatebuffered saline (PBS) and incubated with anti-rFBA antibody at a 1:1000 dilution, then with tetraethyl rhodamine isothiocyanate (TRITC)-tagged anti-IgG (Proteintech, 1:500 dilution). Finally, cell nuclei were stained with 6-diamidino-2-phenylindole (DAPI). Fluorescence was detected using a fluorescence microscope (Zeiss, Germany). BSA was used instead of rFBA as a negative control [36].

\section{Inhibition of adherence using antibody recognising rFBA}

Mycoplasma hyopneumoniae cells $\left(1 \times 10^{7} \mathrm{CCU} /\right.$ $\mathrm{mL}$ ) were washed three times with PBS and pre-incubated with polyclonal antibody raised against rFBA or preimmune sera (1:20 dilution) at $37{ }^{\circ} \mathrm{C}$ for $30 \mathrm{~min}$. Bacteria suspended in RPMI-1640 medium were added to 24-well cell plates containing confluent STEC, and plates were centrifuged at $800 \times g$ for $10 \mathrm{~min}$ and incubated at $4{ }^{\circ} \mathrm{C}$ for $2 \mathrm{~h}$. Bacteria counting including bacterial genome extraction and real-time PCR was performed according to a previous method [19, 37]. The assay was performed in triplicate, and data were analysed using Student's $t$ tests with SPSS 20.0 ( $p \leq 0.05$ was considered statistically significant).

\section{Far-Western blot analysis of rFBA with fibronectin}

To explore whether $M$. hyopneumoniae FBA could bind to fibronectin, the Far-Western blot (Far-WB) proteinprotein interaction method was performed. A $20 \mu \mathrm{g}$ sample of rFBA was separated by SDS-PAGE and transferred to a PVDF membrane [36]. After blocking with 5\% (w/v) skimmed milk, the membrane was incubated with $5 \mu \mathrm{g} /$ $\mathrm{mL}$ fibronectin (Sigma), followed by incubation with rabbit anti-fibronectin antibody (Boster; $1 \mu \mathrm{g} / \mathrm{mL}$ ) as the primary antibody, and horseradish peroxidase (HRP)conjugated goat anti-rabbit IgG (Boster; 1:5000 dilution) as the secondary antibody. Finally, the membrane was developed with Electro-Chemi-Luminescence (ECL) substrate using a ChemiDoc XRS+ system (Bio-Rad). BSA was used instead of rFBA as a negative control, and polyclonal antibody against rFBA was used as a positive control.

\section{Surface plasmon resonance analysis}

The interaction dynamics of rFBA and fibronectin were further investigated in real time by surface plasmon resonance (SPR) using a BIAcore X100 Plus instrument (GE Healthcare). Fibronectin was diluted to $10 \mu \mathrm{g} / \mathrm{mL}$ in $10 \mathrm{mM}$ sodium acetate $(\mathrm{pH} 4.0)$ and covalently linked to the carboxymethylated dextran matrix of a CM5 sensor chip as the ligand using an amine coupling kit (Biacore $\mathrm{AB})$. Immobilisation of soluble fibronectin generated resonance units (RU) of 2868. Binding kinetics were measured with increasing concentrations $(0-100 \mu \mathrm{g} / \mathrm{mL})$ of the analyte (rFBA) in running buffer (HBS-EP) consisting of $10 \mathrm{mM}$ HEPES, $150 \mathrm{mM} \mathrm{NaCl}, 3 \mathrm{mM}$ EDTA, and $0.05 \%(\mathrm{v} / \mathrm{v})$ surfactant P20 (Biacore AB) at a flow rate of $30 \mu \mathrm{L} / \mathrm{min}$ for $180 \mathrm{~s}$ over immobilised fibronectin at $20{ }^{\circ} \mathrm{C}$. The dissociation phase was monitored for $1000 \mathrm{~s}$ by allowing the buffer to flow over the chip. Association kinetics were analysed manually using Biacore X100 Control Software [11].

\section{Results}

Clinical observation and lung lesion scoring

At 14 days after treatment, pigs from the group challenged with $M$. hyopneumoniae strain 168 began to 
cough, while no clinical signs of pneumonia were observed from the group challenged with M. hyopneumoniae strain 168L or the control group. All pigs were alive during the entire experimental period. After euthanising, each of the seven pulmonary lobes was scored for severity of mycoplasmal lesions ranging from 0 to $4(0=$ absence of lobular pneumonia; $1=1-25 \%$ lesions; $2=26-50 \%$ lesions; $3=51-75 \%$ lesions; $4=76-100 \%$ lesions). The results show that lung lesion levels indicated by the sum of seven pulmonary lobes in the group challenged with M. hyopneumoniae strain 168 (average lung lesion score 12) were significantly higher than those in the group challenged with strain 168L (average lung lesion score 1) (Figure 1). The main lesion of the strain 168 challenged group is the pulmonary consolidation in the cranial and middle lobes of lungs, and the lesions have obvious boundaries with the non-lesioned areas. Thus, M. hyopneumoniae strain 168 was more virulent than strain 168L.

\section{Identification of differentially abundant proteins} by comparative proteomic analysis

Proteins $\geq 1.5$-fold more abundant in the $M$. hyopneumoniae strain 168 were considered differentially abundant and subjected to MALDI-TOF-MS/MALDITOF-TOF-MS analysis. Seven differentially abundant proteins were successfully identified; the molecular chaperone DnaK, elongation factor Tu (EF-Tu), glyceraldehyde 3-phosphate dehydrogenase (GAPDH), adenine phosphoribosyltransferase (Apt), lactate dehydrogenase (LDH), heat shock protein GrpE, and FBA. DnaK, GAPDH and FBA were not detected in lysates of strain $168 \mathrm{~L}$ by $2-\mathrm{DE}$ analysis, indicating that they were expressed at very low levels in the attenuated strain. However, FBA showed relatively higher expression in M. hyopneumoniae 168 based on 2D gels, and received a higher score in MS analysis (Figure 2 and Table 1).

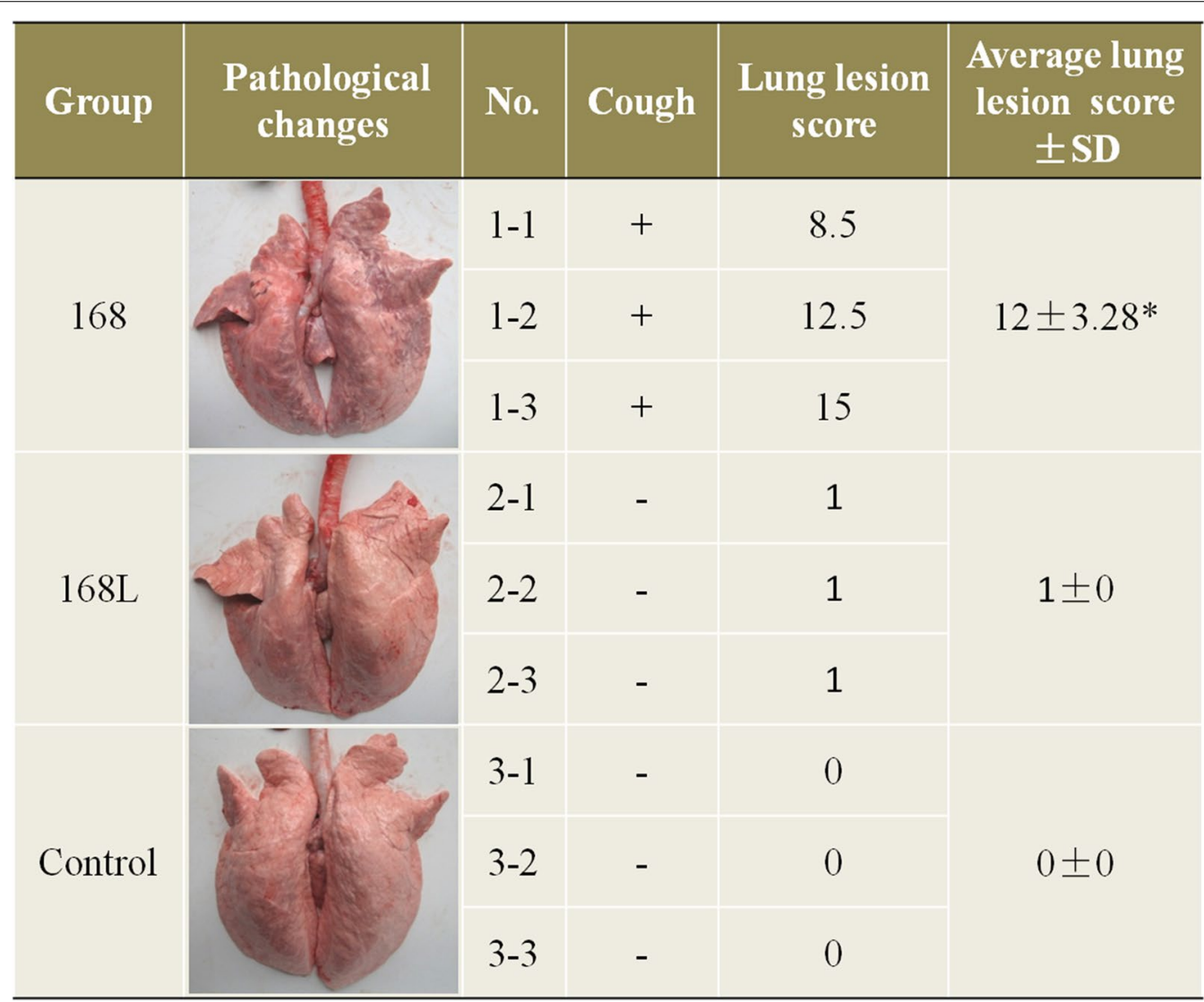

Figure 1 Evaluation of virulence in Mycoplasma hyopneumoniae strains 168 and 168L. After treatment, piglets challenged with strain 168 showed symptoms of coughing, but no clinical signs of pneumonia were observed in the $168 \mathrm{~L}$ or control groups. All pigs were alive during the entire experimental period. Lung lesion scores were subjected to statistical analysis after slaughter. The main lung lesion of the strain 168 challenged group is the pulmonary consolidation in the cranial and middle lobes of the lungs, and the lesions have obvious boundaries with the non-lesioned areas. Significant differences were observed between groups challenged with M. hyopneumoniae strain 168 and $168 \mathrm{~L}(p<0.05)$. 

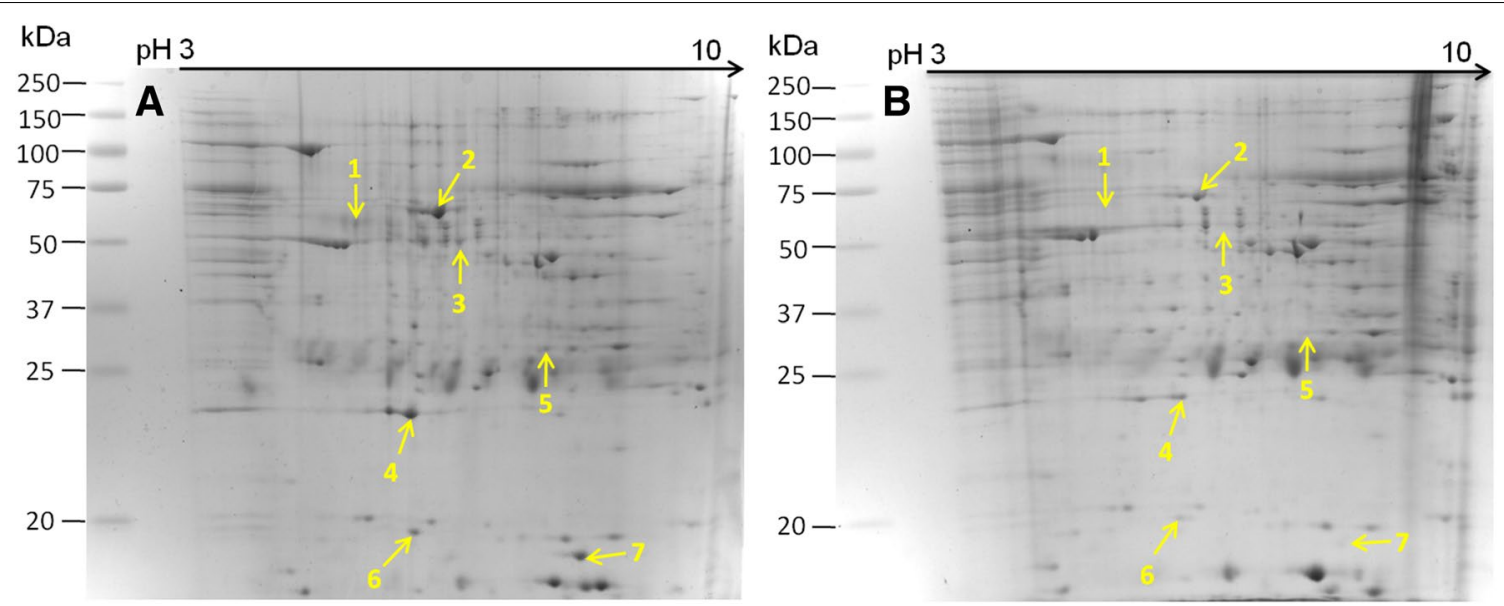

Figure 2 Identification of differentially abundant proteins by two-dimensional electrophoresis (2-DE). A Bacterial proteins from $M$. hyopneumoniae strain 168 cultured in KM2 medium. B Bacterial proteins from M. hyopneumoniae strain 168L cultured in KM2 medium. Yellow arrows on gel images indicate the seven protein spots listed in Table 1 increased in abundance by $\geq 1.5$-fold in M. hyopneumoniae strain 168 .

Table 1 The proteins with significant changes in abundance

\begin{tabular}{|c|c|c|c|c|c|c|}
\hline Spot no. & Protein description & Fold change & Mascot score ${ }^{a}$ & Theoretical pl/Mw & $\begin{array}{l}\text { Sequence } \\
\text { coverage }(\%)\end{array}$ & Accession \\
\hline 1 & Molecular chaperone DnaK (DnaK) & + & 179 & $5.17 / 68281.56$ & 6 & ADQ90292.1 \\
\hline 2 & Elongation factor Tu (EF-Tu) & 1.88 & 711 & $5.61 / 44122.49$ & 27 & ADQ90729.1 \\
\hline 3 & $\begin{array}{l}\text { Glyceraldehyde 3-phosphate dehydroge- } \\
\text { nase (GAPDH) }\end{array}$ & + & 198 & $6.67 / 36873.02$ & 11 & ADQ90256.1 \\
\hline 4 & Adenine phosphoribosyltransferase (Apt) & 1.94 & 216 & $5.34 / 18849.21$ & 22 & ADQ90402.1 \\
\hline 5 & L-Lactate dehydrogenase (LDH) & 1.72 & 442 & $8.29 / 34237.25$ & 20 & ADQ90382.1 \\
\hline 6 & Heat shock protein (GrpE) & 1.97 & 87 & $5.47 / 28854.10$ & 6 & ADQ90239.1 \\
\hline 7 & Fructose-bisphosphate aldolase (FBA) & + & 342 & $9.05 / 43780.88$ & 20 & ADQ90241.1 \\
\hline
\end{tabular}

${ }^{a}$ Mascot computes a score based on the probability that the peptides from a sample match those in the selected protein database. The more peptides Mascot identifies from a particular protein, the higher the Mascot score for that protein.

"+" Means those proteins that only observed in the 2-DE map of M. hyopneumoniae strain 168, which means its expression level in strain $168 \mathrm{~L}$ is very low.

\section{Network analysis of novel differentially abundant proteins and known putative virulence factors}

A protein-protein interaction network was constructed to explore the possible contributions of the seven differentially abundant proteins to the virulence of $M$. hyopneumoniae. The results revealed a total of 45 direct physical interactions among the 18 nodes (Figure 3 and Additional file 1). Amongst these, 16 interactions had a score $>0.70$ (i.e., high confidence), implicating all seven proteins in the interaction network of known virulence factors. The novel differentially abundant proteins (orange nodes) are strongly linked to each other as well as to known virulence factors (green nodes), connected to previously reported putative virulence factors, and form important hub proteins. These results indicate that these seven proteins may play a role in virulence.

\section{Core genes encoding proteins are involved in $M$. hyopneumoniae virulence}

Proteome-wide analysis revealed that most of the novel virulence-associated proteins were pivotal enzymes involved in bacterial growth and metabolism. This encouraged us to explore the commonality of virulenceassociated factors from a systematic stand point. A pangenomic analysis with nine available $M$. hyopneumoniae genomes was therefore performed, resulting in 1152 shared genes, including 481 core genes and 671 dispensable genes. The size of the pan-genome increased when a greater number of sequenced genomes are included, but the core genome decreased in size (Figure $4 \mathrm{~A}$ ). The predicted core genome and pan-genome of $M$. hyopneumoniae is shown in the form of a flowerplot schematic diagram (Figure 4B). Unexpectedly, six 


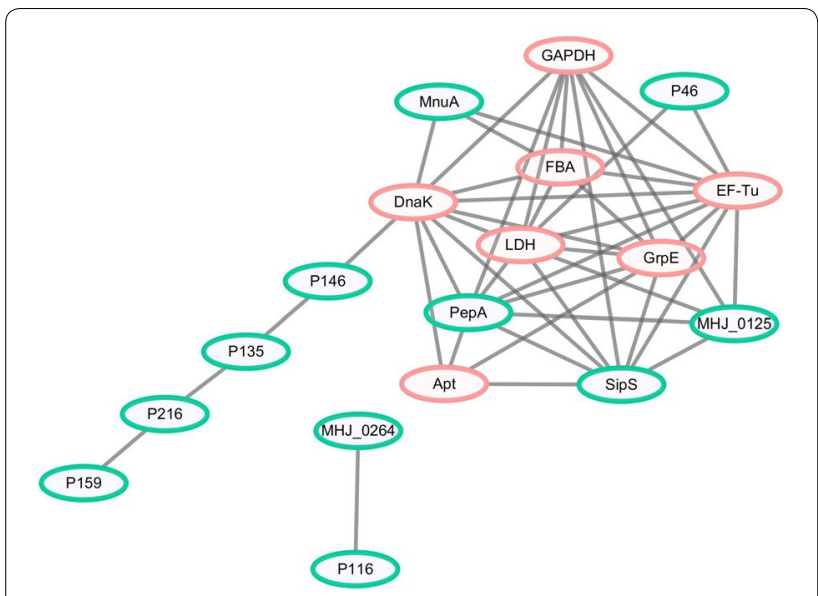

Figure 3 Interaction networks of the identified differentially abundant proteins and known putative virulence factors.

Protein-protein interactions of differentially abundant proteins with a confidence score $\geq 0.4$ are shown. Green nodes represent known putative virulence factors collected from published literature, and orange nodes represent differentially abundant proteins in $M$. hyopneumoniae strain 168 compared with strain 168L. Grey lines represent interactions between two nodes.

of the seven novel differentially abundant proteins were encoded by core genes. Only Apt was absent from the genome of M. hyopneumoniae strain 11, for which only a draft genome sequence is available (Additional file 2). This indicates that in addition to peripheral or unique genes, core genes can also play an important role in $M$. hyopneumoniae virulence.

\section{Western blot validation of the results of comparative proteomics analysis}

FBA was selected for validation of the comparative proteomics analysis and for further studies, because it showed the most fold change of all seven differentially abundant proteins, it received a higher score in the MS analysis, and it is encoded by a core gene. The results of Western blotting show that FBA expression was increased significantly in M. hyopneumoniae strain 168 compared with that in strain 168L (Figure 5). Thus, upregulation of FBA was shown to be consistent using both approaches.

\section{Flow cytometry reveals surface localisation of FBA in $M$. hyopneumoniae 168}

There was no significant difference in mean fluorescence intensity (MFI) between M. hyopneumoniae strain 168L treated with anti-rFBA serum and strain 168L incubated with preimmune serum, whereas the MFI of strain 168 treated with anti-rFBA serum was 3.7-fold higher than that of strain 168 treated with preimmune serum (Figure 6). Flow cytometry results demonstrate that outer membrane-localised FBA was surface-accessible to FBAspecific antibody in strain 168, FBA antigen was present on the bacterial cell surface of M. hyopneumoniae strain 168. In addition, the fold-change in MFI of strain 168 incubated with anti-rFBA compared with preimmune

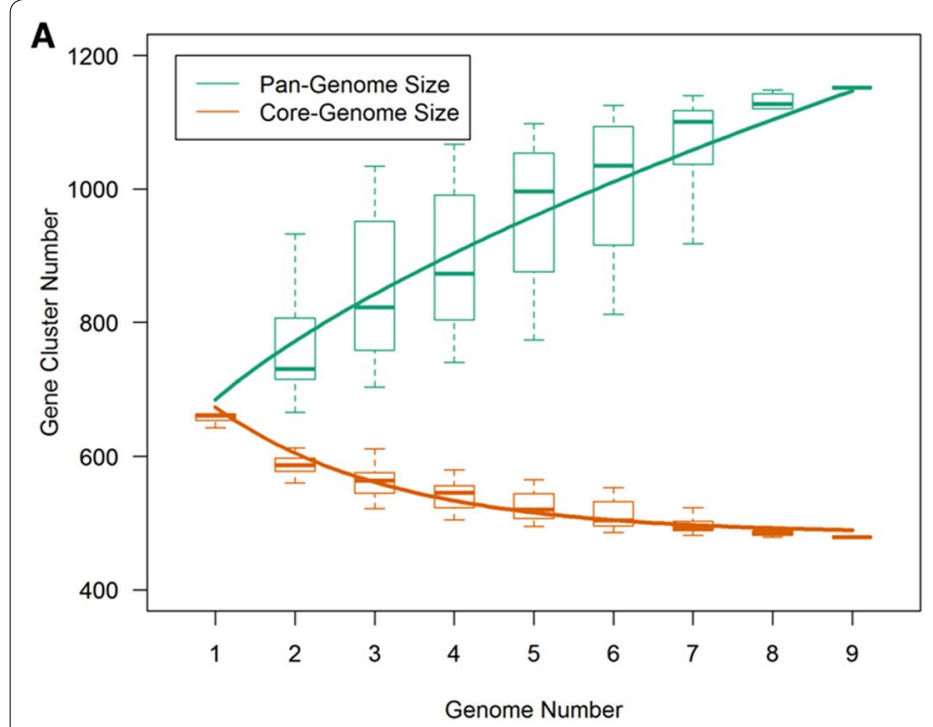

B

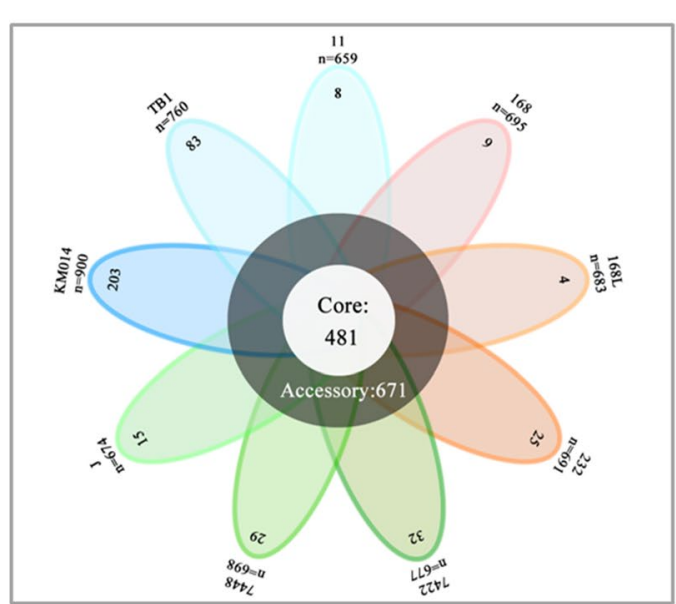

Figure 4 Predicted size of the pan-genome of $\boldsymbol{M}$. hyopneumoniae. A Comparative overview of the pan-genome and core genome of $\mathbf{M}$. hyopneumoniae. The M. hyopneumoniae pan-genome is shown in green (1152 genes), while the core genome is shown in orange (481 genes). Each plot point represents the mean value for gene clusters in the respective number of genomes, and curves represent power law fitting of the data. B Flower-plot schematic diagram of all nine M. hyopneumoniae strains for which genome data are available, showing the core genome size (flower centre) and the number of unique genes for each strain (flower petals). Numbers below the name of each strain indicate the total number of genes. 

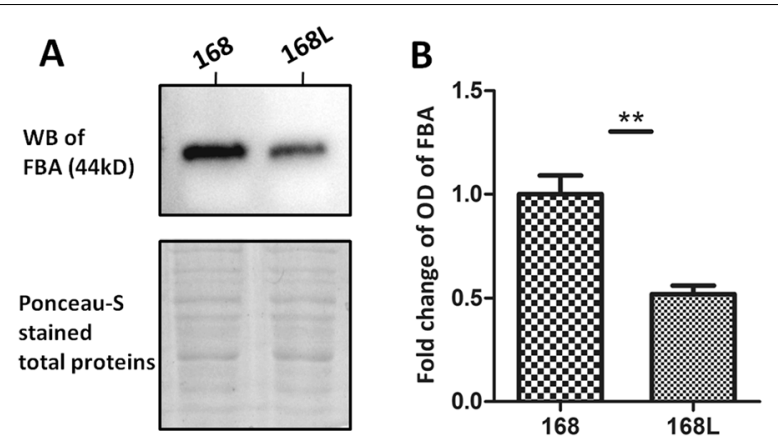

Figure 5 Western blot analysis of comparative proteomics data. A The left lane was loaded with bacterial proteins from $M$. hyopneumoniae strain 168. The right lane was loaded with bacterial proteins from strain 168L. The differentially abundant protein fructose-1,6-bisphosphate aldolase (FBA; $44 \mathrm{kDa}$ ) was analysed using the corresponding antibodies. Protein bands were visualised using Electro-Chemi-Luminescence (ECL) substrate. A Ponceau-S stained membrane was used as the loading control. B Image J software was used to calculate the optical density of the corresponding bands in the blots. The optical density of the corresponding bands was normalized to the total proteins of Ponceau-S staining of the same membrane. The level of abundance of FBA in $M$. hyopneumoniae strain $168 \mathrm{~L}$ is expressed as the percentage of that in M. hyopneumoniae strain 168. The asterisk above the charts stands for statistically significant differences.

serum was significantly higher than that in strain $168 \mathrm{~L}$. This difference indicates that the surface abundance of FBA is significantly higher in strain 168 than in strain $168 \mathrm{~L}$.

\section{Indirect immunofluorescence reveals adherence of rFBA to STEC}

To explore the potential mechanism(s) by which surface localisation of FBA affects virulence, we used indirect immunofluorescence to determine whether rFBA could adhere to STEC. The results revealed significant fluorescence on the cell surface of STEC incubated with rFBA (Figure 7A), but no specific fluorescence was observed around DAPI-stained cell nuclei in negative controls (Figure 7B). The results provide direct evidence that rFBA binds specifically to the cell membranes of STEC.

\section{Confirmation of adherence by antibody inhibition assay}

Antibody inhibition assays were performed to further assess the contribution of surface-localised FBA to adhesion in M. hyopneumoniae strain 168. A polyclonal antibody against rFBA was found to decrease $M$. hyopneumoniae adherence to STEC relative to treatment with preimmune sera (Figure 8). The level of adherence is expressed as the percentage of M. hyopneumoniae adherence without antibody. Incubation with anti-rFBA antibody resulted in a $76 \%(p<0.05)$ reduction in the adherence efficiency of M. hyopneumoniae to STEC, further confirming that FBA plays an indispensable role in adherence of M. hyopneumoniae to host cells.

\section{rFBA binds specifically to fibronectin}

To investigate the STEC components that interact with FBA, we examined the fibronectin-binding activity of rFBA using Far-WB analysis. The corresponding bands were observed in both reactions of rFBA to anti-FBA antibody (positive control) and to fibronectin, while no specific reaction was observed in the negative control. The analysis indicates that rFBA could specifically bind to fibronectin (Figure 9A). Using surface plasmon resonance (SPR), the real-time interactions between $\mathrm{rFBA}$ and fibronectin were further investigated (Figure 9B). The results were consistent with those expected for a specific, moderately strong interaction between proteins of this size, and rFBA was found to bind fibronectin in a dose-dependent and physiologically relevant manner, with $K_{\mathrm{D}}=468 \pm 23 \mathrm{nM}$ and $k_{\mathrm{a}}=3470 \pm 580 \mathrm{M}^{-1} \mathrm{~s}^{-1}$.

\section{Discussion}

The pan-genome includes the core genome containing genes present in all individuals, the accessory or dispensable genome containing genes present in two or more strains, and unique genes specific to single strains [33]. The expression of special elements encoded in the accessory genome, especially unique genomic elements carried by pathogenic strains, is generally considered to be associated with virulence [38]. For example, Escherichia coli strains include 1200 genes in the conserved core genome, but more than 13000 gene families in the pan-genome. This is in part due to several major virulence factors being located on transmissible genetic elements such as pathogenicity islands, bacteriophages, or plasmids, which are classed as accessory genes [38]. Similarly, Shiga toxin, encoded by $s t x$, is a bacteriophage element [39], and the adhesion and Shiga virulence factor intimin is encoded by eae, which belongs to a pathogenicity island.

Although accessory genes encode many conspicuous determinants of virulence, core genes can also confer appreciable virulence. Indeed, more and more moonlighting proteins are being recognised with roles in bacterial pathogenesis [40]. Moonlighting proteins, exhibiting two or more biochemical functions using a single polypeptide chain [41], are commonly encoded by the core genome, and are often enzymatically active with cytoplasmic roles in glycolysis or other metabolic pathways. However, such proteins are often displayed on the surface of bacteria, where they perform functions unrelated to their cytoplasmic roles that may be associated with virulence, and many interact with a variety of host ligands [42]. 

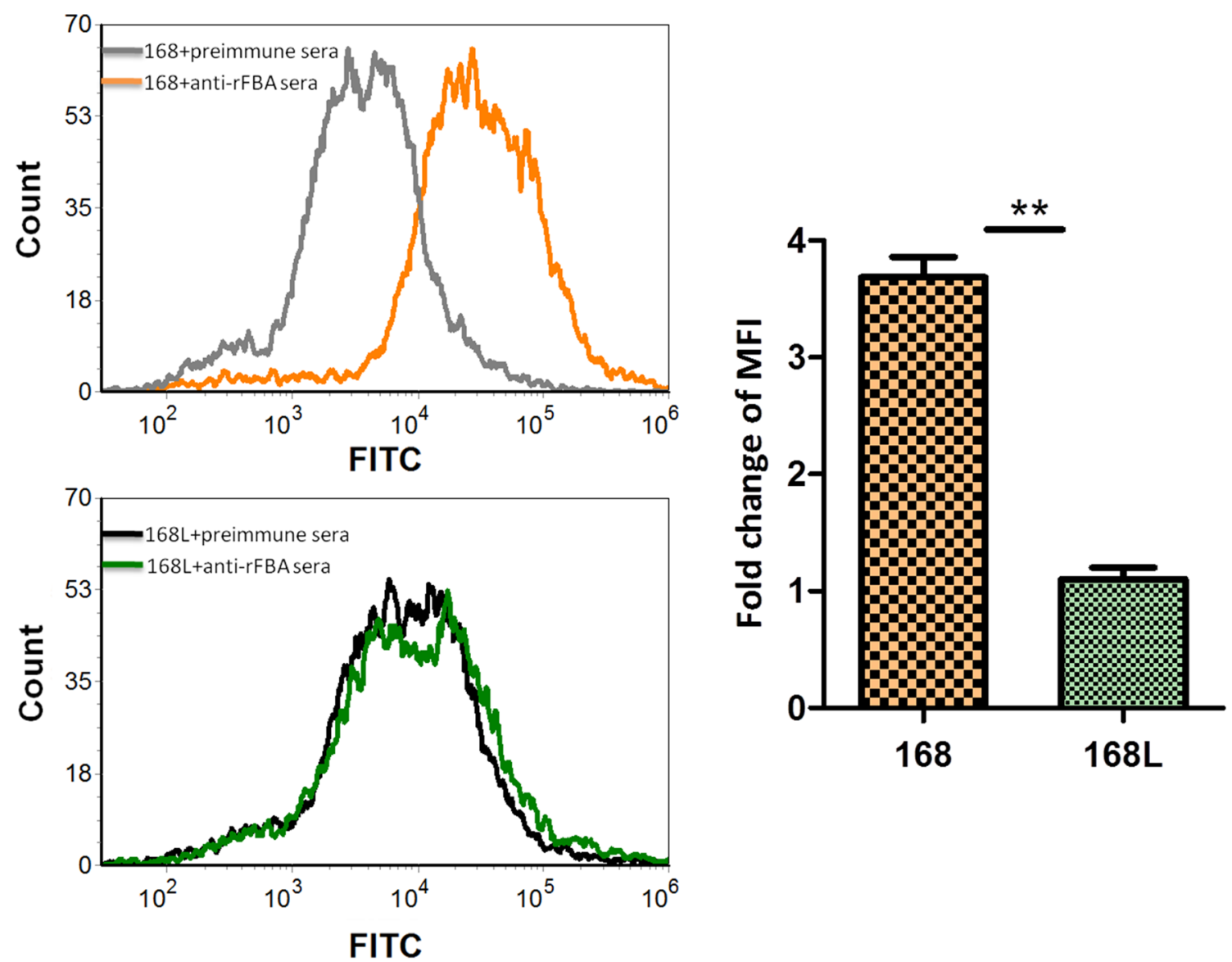

Figure 6 Detection of FBA on the surface of $\boldsymbol{M}$. hyopneumoniae by flow cytometry. Negative control, M. hyopneumoniae strain 168 and $168 \mathrm{~L}$ treated with preimmune serum; M. hyopneumoniae strain 168 and 168L: bacteria treated with anti-rFBA serum. The level of mean fluorescence intensity (MFI) of $M$. hyopneumoniae incubated with anti-rFBA sera is expressed as the percentage of the corresponding strain incubated with preimmune sera. The asterisks above the charts stand for statistically significant differences.

In the present study, 2-DE analysis revealed that seven proteins were significantly increased in abundance in the virulent M. hyopneumoniae strain. A virulence-associated network constructed using these seven proteins and previously reported putative virulence factors showed that all seven novel differentially abundant proteins are involved in M. hyopneumoniae virulence. Since all seven are conserved enzymes, we explored a possible common pattern among these virulence-associated factors from a system and whole-genome perspective. A pan-genomics analysis with nine available $M$. hyopneumoniae genomes was therefore performed. Unexpectedly, six of the seven novel differentially abundant proteins are encoded by core genes, and the only protein potentially encoded by an accessory gene may not be in reality due to incomplete sequencing of strain 11. This indicates that core genes, which are often neglected, can play an important role in M. hyopneumoniae virulence.
Of the seven proteins, FBA showed the most fold change in different virulence $M$. hyopneumoniae strains, and this protein is a promising therapeutic and vaccine target in bacteria [43]. FBA is a ubiquitous metabolic enzyme occupying a central position in glycolysis and gluconeogenesis pathways [44]. Two different classes of FBA (Class-I and -II) have been described based on amino acid sequences [45]. Class-I FBA are usually found in higher eukaryotic organisms (animals and plants), while Class-II FBA are commonly found in bacteria, archaea and lower eukaryotes [46].

Despite lacking identifiable secretion signals, FBA are also localised at the bacterial cell surface, where they interact directly with host proteins and exhibit non-glycolytic functions. Remarkably, FBA has been recently reported to play a role in the pathogenesis of several pathogens. FBA is antigenic in humans, and affords significant protection against challenge with virulent Streptococcus pneumoniae in mice [47]. S. pneumoniae FBA is a cell wall-localised 

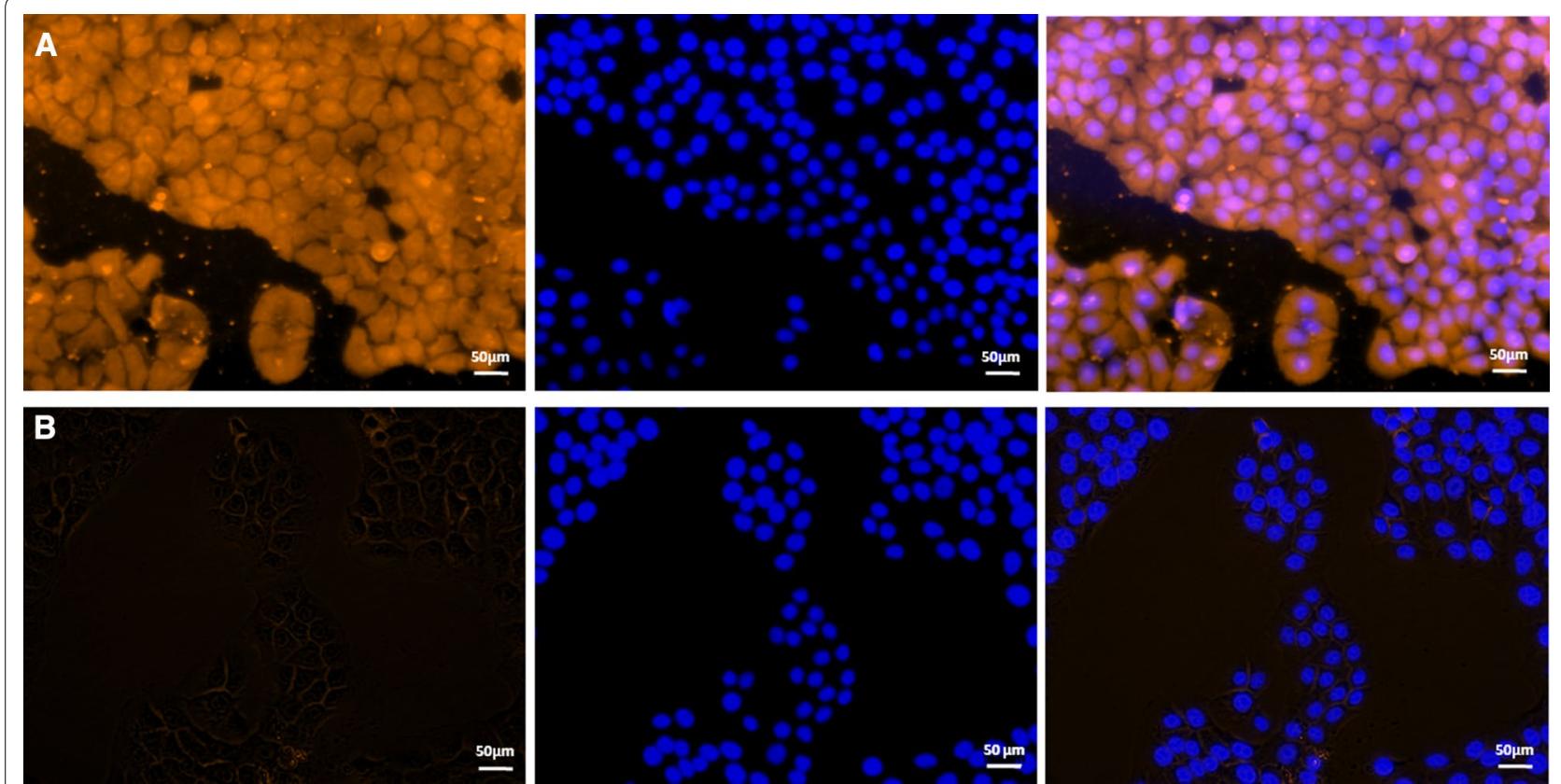

Figure 7 Role of rFBA in adhesion of $\boldsymbol{M}$. hyopneumoniae to swine tracheal epithelial cells (STEC). Blue indicates STEC nuclei. Orange indicates $\mathbf{A}$ rFBA adhering to STEC membranes, and B BSA (negative control) adhering to STEC membranes. The left panel means protein adhered to the STEC membranes. The protein was labelled with tetraethyl rhodamine isothiocyanate (TRITC). The middle panel means cell nuclei of STEC stained with 6-diamidino-2-phenylindole (DAPI). The right panel means the merge of the left and middle panel. The white line indicates the scale.

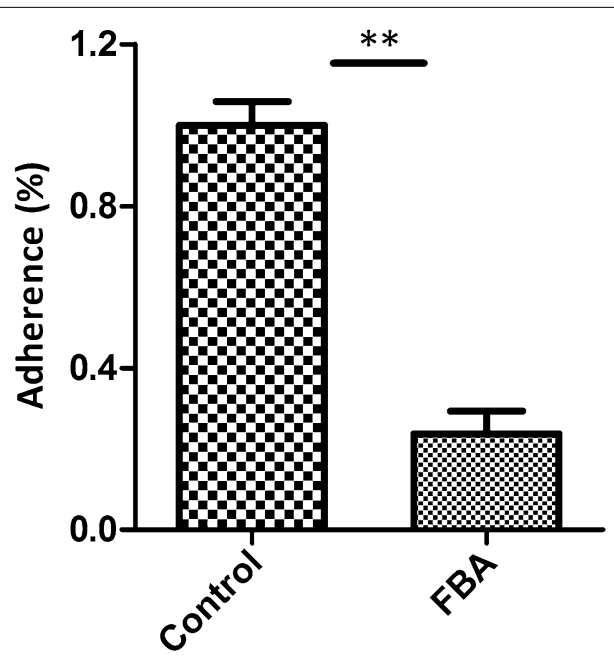

Figure 8 Inhibition of $M$. hyopneumoniae adhesion to STEC. Adhesion rate $=$ (number of bacteria recovered from cells incubated with anti-rFBA sera/number of bacteria recovered in the group incubated with preimmune sera) $\times 100$. Data are expressed as mean \pm SD of at least three experiments with samples performed in triplicate. The asterisks above the charts stand for statistically significant differences.

protein, and anti-rFBA antibodies can inhibit S. pneumoniae adherence to epithelial cells. Flamingo cadherin has been identified as the host receptor [48]. FBA from Streptococcus suis, which is reasonably well conserved among
S. suis strains, was verified as an immunogenic cell wall protein, suggesting it could be developed as a vaccine candidate [49]. FBA of Neisseria meningitidis is localised both in the cytoplasm and the outer membrane, and is required for adhesion to human cells [50] by binding to plasminogen [51]. In Mycobacterium tuberculosis, FBA is required for survival during the chronic phase of mouse infection [52]. FBA has also been shown to be essential for replication and virulence in Toxoplasma gondii [53], and FBA from Francisella novicida is important for bacterial multiplication in macrophages, and plays a regulatory role in pathogenesis [44].

Our flow cytometry analysis indicates that FBA was accessible on the surface of the highly virulent $M$. hyopneumoniae 168 strain, but less so on the attenuated 168L strain. Adherence of viable M. hyopneumoniae strain 168 to STEC was inhibited significantly by anti-rFBA antisera, which indicates that FBA is indispensable for adherence to STEC. These results demonstrate that M. hyopneumoniae FBA, in addition to its major cytoplasmic, biosynthetic, and metabolic roles, can translocate to the surface and moonlight as an important adhesion factor.

Colonising the epithelial surfaces of the respiratory tract is an important part of the pathogenesis of $M$. hyopneumoniae. Since adherence to host tissues is an important prerequisite for colonisation and subsequent disease development for pathogenic bacteria, adhesins 
A

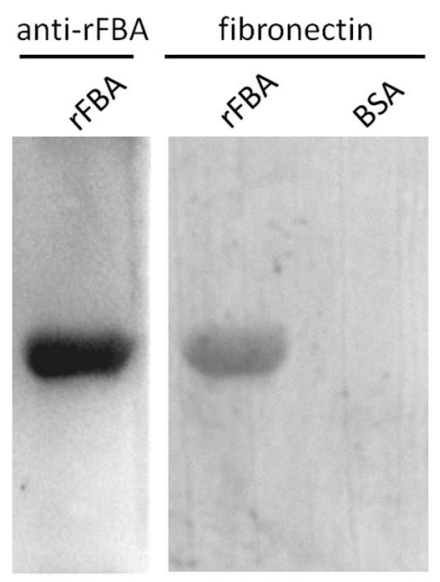

B

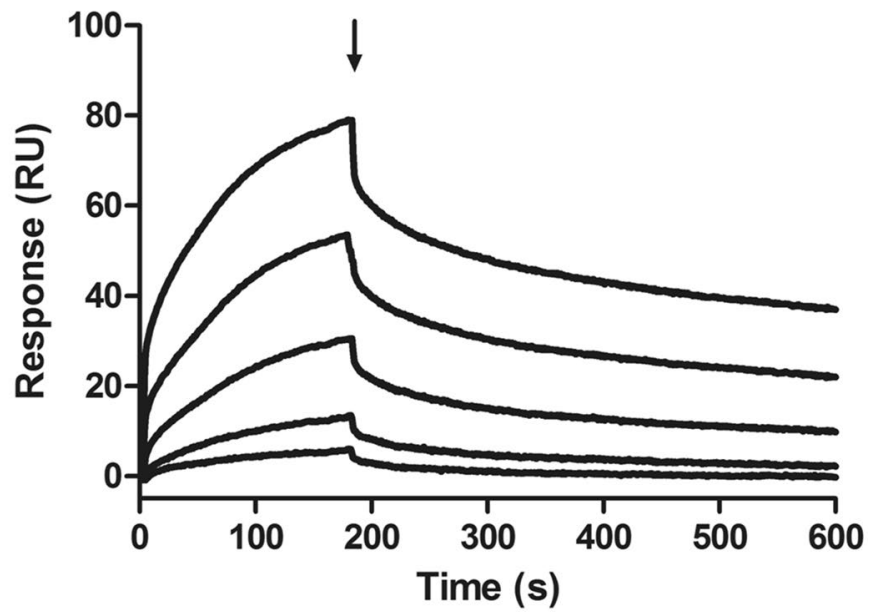

Figure 9 rFBA and fibronectin interaction analysis by Far-WB and Surface plasmon resonance (SPR) analysis. A Far-WB analysis of $r F B A$ with fibronectin. The first lane: PVDF membrane with transferred rFBA protein incubated with anti- rFBA antibody as a positive control; the second lane: PVDF membrane with transferred rFBA protein incubated with fibronectin and anti-fibronectin antibody; the third lane: PVDF membrane with transferred BSA (negative control) incubated with fibronectin and anti-fibronectin antibody. Protein bands were visualized using ECL substrate. B Sensorgrams depict the binding of immobilised fibronectin to rFBA. Increasing concentrations of rFBA $(5,10,25,50$ and $100 \mu \mathrm{mg} / \mathrm{mL})$ were injected at a flow rate of $30 \mu \mathrm{L} / \mathrm{min}$ for 180 s over immobilised fibronectin. The arrow indicates the end of the injection period, at which point dissociation of rFBA from fibronectin can be observed. $R U$ resonance units.

are of crucial importance for M. hyopneumoniae infection [54]. Bacterial adhesion factors frequently interact with extracellular matrix (ECM) components, most commonly fibronectin $[55,56]$, an abundant glycoprotein deposited on cell surfaces [57]. Immunohistochemical staining showed that fibronectin is freely available in the trachea and bronchioles of the porcine lung, especially along the borders of cilia [19], the most common site of colonisation for M. hyopneumoniae. The capacity to bind fibronectin is widespread in bacterial pathogens, and among mycoplasmas, the first fibronectin interaction was identified in $M$. penetrans [58], followed by $M$. pneumoniae [59] and M. hyopneumoniae [11]. Many fibronectin-binding proteins have been identified, such as the microbial surface components recognising the adhesive matrix molecule (MSCRAMM) family of proteins identified in Streptococcus [60] and Staphylococcus [61]. The mammalian fibronectin system is widely-used by pathogens as a virulence strategy. In our previous work, blocking fibronectin in STEC decreased M. hyopneumoniae adherence to the cell surface. Consistently, fibronectin was verified as one of the host cell receptors for M. hyopneumoniae adhesion [19]. The dissociation constant for rFBA and fibronectin determined by SPR was $K_{\mathrm{D}}$ of $468 \mathrm{nM}$, signifying a specific and moderately strong interaction that may be physiologically relevant. This is the first report of an interaction between FBA of $M$. hyopneumoniae and host fibronectin contributing to adherence and therefore pathogenicity.
In summary, our research indicates the importance of core genes in the virulence of $M$. hyopneumoniae. Specifically, FBA is abundant on the surface of virulent $M$. hyopneumoniae strains, where it binds strongly to host fibronectin, thereby promoting adherence to STEC. FBA can be surface translocated and may play a role in the adhesion to host cells and colonisation, thereby serving as an important candidate virulence factor of $M$. hyopneumoniae. Thus, we can conclude that core enzymes may be important virulence determinants. To our knowledge, this is the first report describing the moonlighting function of FBA in M. hyopneumoniae virulence, and the first to present evidence of the involvement of core genes in virulence in this species. Intrinsic virulence functions represent potential targets for broad-spectrum drugs, and links between intrinsic gene functions and virulence traits are clearly worthy of further study. For organisms with relatively small genomes, multi-functional proteins may be particularly useful for optimising the potential of the genome [50]. However, only nine M. hyopneumoniae genomes are currently available, which may limit pan-genome analysis to some extent. Indeed, only partial inhibition of FBA was observed in competitive adhesion inhibition assays.

In conclusion, the core genome encoding proteins located in the cytoplasm and the cell membrane appears to be associated with virulence in M. hyopneumoniae. Much remains to be elucidated about how proteins lacking signal motifs are localised on the bacterial cell surface. The roles of core genome encoding proteins 
in infection and immunity in M. hyopneumoniae and other pathogenic organisms are clearly worthy of further investigation.

The combined comparative proteomics and core genomics analyses employed herein successfully identified potential virulence-associated factors in M. hyopneumoniae. Among these factors, FBA does not have a pig ortholog, making it a prime candidate for a swine pneumonia vaccine. Our comprehensive analysis revealed seven virulence-associated factors, at least six of which are encoded in the core genome of M. hyopneumoniae. The current lack of effective vaccine candidates and the global expansion of sequencing data make this a potentially powerful approach for the identification and development of effective vaccines against $M$. hyopneumoniae and other bacterial pathogens.

\section{Additional files}

Additional file 1. Protein-protein interaction network. Network analysis of novel differentially abundant proteins and known putative virulence factors of M. hyopneumoniae by String database.

Additional file 2. Pan-genomic analysis. A pan-genomic analysis with nine available $M$. hyopneumoniae genomes.

\section{Competing interests}

The authors declare that they have no competing interests.

\section{Authors' contributions}

YY completed the study of the pathogenic mechanism of FBA and prepares the manuscript. The comparative proteomics analysis was done by ML and MQ. LH prepared the recombinant protein. YG performed the animal experiments. YW helped with the cell adhesion experiments. ZF and GS modified the manuscript. QX and WZ supervised and guided this work. All authors read and approved the final manuscript.

\section{Acknowledgements}

We would like to thank the native English speaking scientists of Elixigen Company (Huntington Beach, California) for editing our manuscript. This work was supported by the National Natural Science Foundation of China [Grant Numbers 31370208, 31700158, 31400164], the Postdoctoral Foundation of Jiangsu Province, China [Grant Number 1701004A], and the Natural Science Foundation of Jiangsu Province, China [Grant Number BK20140754].

\footnotetext{
Author details

${ }^{1}$ Key Laboratory of Veterinary Biological Engineering and Technology of Ministry of Agriculture, Institute of Veterinary Medicine, Jiangsu Academy of Agricultural Sciences, Nanjing, China. ${ }^{2}$ Key Lab of Food Quality and Safety of Jiangsu Province-State Key Laboratory Breeding Base, Nanjing, China. ${ }^{3}$ College of Animal Science and Technology, Shanxi Agricultural University, Taigu, China. ${ }^{4}$ Key Lab of Animal Bacteriology of Ministry of Agriculture, College of Veterinary Medicine, Nanjing Agricultural University, Nanjing, China.
}

\section{Publisher's Note}

Springer Nature remains neutral with regard to jurisdictional claims in published maps and institutional affiliations.

Received: 20 August 2018 Accepted: 16 October 2018

Published online: 19 November 2018

\section{References}

1. DeBey MC, Ross RF (1994) Ciliostasis and loss of cilia induced by Mycoplasma hyopneumoniae in porcine tracheal organ cultures. Infect Immun 62:5312-5318

2. Thacker EL, Minion FC (2010) Mycoplasmosis. In: Zimmerman J (ed) Diseases of Swine. lowa State University Press, Ames

3. Maes D, Sibila M, Kuhnert P, Segales J, Haesebrouck F, Pieters M (2017) Update on Mycoplasma hyopneumoniae infections in pigs: knowledge gaps for improved disease control. Transbound Emerg Dis 65:110-124

4. Zhang Q, Young TF, Ross RF (1995) Identification and characterization of a Mycoplasma hyopneumoniae adhesion. Infect Immun 63:1013-1019

5. Adams C, Pitzer J, Minion FC (2005) In vivo expression analysis of the P97 and P102 paralog families of Mycoplasma hyopneumoniae. Infect Immun 73:7784-7787

6. Seymour LM, Jenkins C, Deutscher AT, Raymond BB, Padula MP, Tacchi JL, Bogema DR, Eamens GJ, Woolley LK, Dixon NE, Walker MJ, Djordjevic SP (2012) Mhp182 (P102) binds fibronectin and contributes to the recruitment of plasmin(ogen) to the Mycoplasma hyopneumoniae cell surface. Cell Microbiol 14:81-94

7. Burnett TA, Dinkla K, Rohde M, Chhatwal GS, Uphoff C, Srivastava M, Cordwell SJ, Geary S, Liao X, Minion FC, Walker MJ, Djordjevic SP (2006) P159 is a proteolytically processed, surface adhesin of Mycoplasma hyopneumoniae: defined domains of P159 bind heparin and promote adherence to eukaryote cells. Mol Microbiol 60:669-686

8. Mayor D, Zeeh F, Frey J, Kuhnert P (2007) Diversity of Mycoplasma hyopneumoniae in pig farms revealed by direct molecular typing of clinical material. Vet Res 38:391-398

9. Wilton J, Jenkins C, Cordwell SJ, Falconer L, Minion FC, Oneal DC, Djordjevic MA, Connolly A, Barchia I, Walker MJ, Djordjevic SP (2009) Mhp493 (P216) is a proteolytically processed, cilium and heparin binding protein of Mycoplasma hyopneumoniae. Mol Microbiol 71:566-582

10. Seymour LM, Deutscher AT, Jenkins C, Kuit TA, Falconer L, Minion FC, Crossett B, Padula M, Dixon NE, Djordjevic SP, Walker MJ (2010) A processed multidomain Mycoplasma hyopneumoniae adhesin binds fibronectin, plasminogen, and swine respiratory cilia. J Biol Chem 285:33971-33978

11. Deutscher AT, Jenkins C, Minion FC, Seymour LM, Padula MP, Dixon NE, Walker MJ, Djordjevic SP (2010) Repeat regions R1 and R2 in the P97 paralogue Mhp271 of Mycoplasma hyopneumoniae bind heparin, fibronectin and porcine cilia. Mol Microbiol 78:444-458

12. Bogema DR, Scott NE, Padula MP, Tacchi JL, Raymond BB, Jenkins C, Cordwell SJ, Minion FC, Walker MJ, Djordjevic SP (2011) Sequence TTKF downward arrow QE defines the site of proteolytic cleavage in Mhp683 protein, a novel glycosaminoglycan and cilium adhesin of Mycoplasma hyopneumoniae. J Biol Chem 286:41217-41229

13. Seymour LM, Falconer L, Deutscher AT, Minion FC, Padula MP, Dixon NE, Djordjevic SP, Walker MJ (2011) Mhp107 is a member of the multifunctional adhesin family of Mycoplasma hyopneumoniae. J Biol Chem 286:10097-10104

14. Copley SD (2012) Moonlighting is mainstream: paradigm adjustment required. BioEssays 34:578-588

15. Robinson MW, Buchtmann KA, Jenkins C, Tacchi JL, Raymond BB, To J, Roy CP, Woolley LK, Labbate M, Turnbull L, Whitchurch CB, Padula MP, Djordjevic SP (2013) MHJ_0125 is an M42 glutamyl aminopeptidase that moonlights as a multifunctional adhesin on the surface of Mycoplasma hyopneumoniae. Open Biol 3:130017

16. Jarocki VM, Santos J, Tacchi JL, Raymond BB, Deutscher AT, Jenkins C, Padula MP, Djordjevic SP (2015) MHJ_0461 is a multifunctional leucine aminopeptidase on the surface of Mycoplasma hyopneumoniae. Open Biol 5:140175

17. Tacchi JL, Raymond BB, Haynes PA, Berry IJ, Widjaja M, Bogema DR, Woolley LK, Jenkins C, Minion FC, Padula MP, Djordjevic SP (2016) Post-translational processing targets functionally diverse proteins in Mycoplasma hyopneumoniae. Open Biol 6:150210

18. Berry IJ, Jarocki VM, Tacchi JL, Raymond BBA, Widjaja M, Padula MP, Djordjevic SP (2017) N-terminomics identifies widespread endoproteolysis and novel methionine excision in a genome-reduced bacterial pathogen. Sci Rep 7:11063

19. Yu Y, Wang H, Wang J, Feng Z, Wu M, Liu B, Xin J, Xiong Q, Liu M, Shao $G$ (2018) Elongation factor thermo unstable (EF-Tu) moonlights as an adhesin on the surface of Mycoplasma hyopneumoniae by binding to fibronectin. Front Microbiol 9:974 
20. Widjaja M, Harvey KL, Hagemann L, Berry IJ, Jarocki VM, Raymond BBA, Tacchi JL, Grundel A, Steele JR, Padula MP, Charles IG, Dumke R, Djordjevic SP (2017) Elongation factor Tu is a multifunctional and processed moonlighting protein. Sci Rep 7:11227

21. Simionatto S, Marchioro SB, Maes D, Dellagostin OA (2013) Mycoplasma hyopneumoniae: from disease to vaccine development. Vet Microbiol $165: 234-242$

22. Pinto PM, Chemale G, de Castro LA, Costa AP, Kich JD, Vainstein MH, Zaha A, Ferreira HB (2007) Proteomic survey of the pathogenic Mycoplasma hyopneumoniae strain 7448 and identification of novel post-translationally modified and antigenic proteins. Vet Microbiol 121:83-93

23. Li YZ, Ho YP, Chen ST, Chiou TW, Li ZS, Shiuan D (2009) Proteomic comparative analysis of pathogenic strain 232 and avirulent strain J of Mycoplasma hyopneumoniae. Biochemistry (Mosc) 74:215-220

24. Yu Y, Qian Y, Du D, Xu C, Dai C, Li Q, Liu H, Shao J, Wu Z, Zhang W (2016) SBP2 plays an important role in the virulence changes of different artificial mutants of Streptococcus suis. Mol BioSyst 12:1948-1962

25. Liu W, Xiao S, Li M, Guo S, Li S, Luo R, Feng Z, Li B, Zhou Z, Shao G, Chen H, Fang $L$ (2013) Comparative genomic analyses of Mycoplasma hyopneumoniae pathogenic 168 strain and its high-passaged attenuated strain. BMC Genomics 14:80

26. Ho CL, Chu T, Chin H, Mao H, Yeh A, Chen C, Chang S, Chang D (1980) Microagglutination test for the diagnosis of swine mycoplasmal pneumonia and the identification of mycoplasmas. Acta Vet Zootech Sin 11:13

27. Huang Y, Haines DM, Harding JC (2013) Snatch-farrowed, porcinecolostrum-deprived (SF-pCD) pigs as a model for swine infectious disease research. Can J Vet Res 77:81-88

28. Huang Y, Ladinig A, Ashley C, Haines DM, Harding JC (2014) Innate and adaptive immune responses of snatch-farrowed porcine-colostrumdeprived pigs to Mycoplasma hyopneumoniae vaccination. BMC Vet Res 10:219

29. Feng ZX, Shao GQ, Liu MJ, Wang HY, Gan Y, Wu XS (2010) Development and validation of a SIgA-ELISA for the detection of Mycoplasma hyopneumoniae infection. Vet Microbiol 143:410-416

30. McIntosh KA, Tumber A, Harding JC, Krakowka S, Ellis JA, Hill JE (2009) Development and validation of a SYBR green real-time PCR for the quantification of Porcine circovirus type 2 in serum, buffy coat, feces, and multiple tissues. Vet Microbiol 133:23-33

31. Madec F, Kobish M (1982) Gross lung lesions of pigs at slaughter. Journées de la Recherche Porcine 14:405-412 (in French)

32. Tettelin H, Masignani V, Cieslewicz MJ, Donati C, Medini D, Ward NL, Angiuoli SV, Crabtree J, Jones AL, Durkin AS, Deboy RT, Davidsen TM, Mora M, Scarselli M, Margarit y Ros I, Peterson JD, Hauser CR, Sundaram JP, Nelson WC, Madupu R, Brinkac LM, Dodson RJ, Rosovitz MJ, Sullivan SA, Daugherty SC, Haft DH, Selengut J, Gwinn ML, Zhou L, Zafar N et al (2005) Genome analysis of multiple pathogenic isolates of Streptococcus agalactiae: implications for the microbial "pan-genome". Proc Natl Acad Sci USA 102:13950-13955

33. Vernikos G, Medini D, Riley DR, Tettelin H (2015) Ten years of pan-genome analyses. Curr Opin Microbiol 23:148-154

34. Zhao Y, Wu J, Yang J, Sun S, Xiao J, Yu J (2012) PGAP: pan-genomes analysis pipeline. Bioinformatics $28: 416-418$

35. Zhu W, Zhang Q, Li J, Wei Y, Cai C, Liu L, Xu Z, Jin M (2017) Glyceraldehyde-3-phosphate dehydrogenase acts as an adhesin in Erysipelothrix rhusiopathiae adhesion to porcine endothelial cells and as a receptor in recruitment of host fibronectin and plasminogen. Vet Res 48:16

36. Li Q, Liu H, Du D, Yu Y, Ma C, Jiao F, Yao H, Lu C, Zhang W (2015) Identification of novel laminin- and fibronectin-binding proteins by Far-Western blot: capturing the adhesins of Streptococcus suis type 2. Front Cell Infect Microbiol 5:82

37. Wu Y, Jin M, Bai F, Zhang X, Hua L, Lei Z (2012) Development and application of TaqMan-BHQ real time PCR assay for detection of Mycoplasma hyopneumoniae P97. Chin Vet Sci 42:1268-1272

38. Barth SA, Menge C, Eichhorn I, Semmler T, Wieler LH, Pickard D, Belka A, Berens C, Geue $L$ (2016) The accessory genome of shiga toxin-producing Escherichia coli defines a persistent colonization type in cattle. Appl Environ Microbiol 82:5455-5464

39. Hoffman MA, Menge C, Casey TA, Laegreid W, Bosworth BT, DeanNystrom EA (2006) Bovine immune response to shiga-toxigenic Escherichia coli O157:h7. Clin Vaccine Immunol 13:1322-1327
40. Henderson B, Martin A (2011) Bacterial virulence in the moonlight: multitasking bacterial moonlighting proteins are virulence determinants in infectious disease. Infect Immun 79:3476-3491

41. Jeffery CJ (1999) Moonlighting proteins. Trends Biochem Sci 24:8-11

42. Wang G, Xia Y, Cui J, Gu Z, Song Y, Chen YQ, Chen H, Zhang H, Chen W (2014) The roles of moonlighting proteins in bacteria. Curr Issues Mol Biol 16:15-22

43. Zhang Y (2005) The magic bullets and tuberculosis drug targets. Annu Rev Pharmacol Toxicol 45:529-564

44. Ziveri J, Tros F, Guerrera IC, Chhuon C, Audry M, Dupuis M, Barel M, Korniotis S, Fillatreau S, Gales L, Cahoreau E, Charbit A (2017) The metabolic enzyme fructose-1,6-bisphosphate aldolase acts as a transcriptional regulator in pathogenic Francisella. Nat Commun 8:853

45. Katebi AR, Jernigan RL (2015) Aldolases utilize different oligomeric states to preserve their functional dynamics. Biochemistry 54:3543-3554

46. Plater AR, Zgiby SM, Thomson GJ, Qamar S, Wharton CW, Berry A (1999) Conserved residues in the mechanism of the E. coli Class II FBP-aldolase. J Mol Biol 285:843-855

47. Ling E, Feldman G, Portnoi M, Dagan R, Overweg K, Mulholland F, ChalifaCaspi V, Wells J, Mizrachi-Nebenzahl Y (2004) Glycolytic enzymes associated with the cell surface of Streptococcus pneumoniae are antigenic in humans and elicit protective immune responses in the mouse. Clin Exp Immunol 138:290-298

48. Blau K, Portnoi M, Shagan M, Kaganovich A, Rom S, Kafka D, Chalifa Caspi V, Porgador A, Givon-Lavi N, Gershoni JM, Dagan R, Mizrachi Nebenzahl Y (2007) Flamingo cadherin: a putative host receptor for Streptococcus pneumonia. J Infect Dis 195:1828-1837

49. Wu Z, Zhang W, Lu C (2008) Immunoproteomic assay of surface proteins of Streptococcus suis serotype 9. FEMS Immunol Med Microbiol 53:52-59

50. Tunio SA, Oldfield NJ, Berry A, Ala'Aldeen DA, Wooldridge KG, Turner DP (2010) The moonlighting protein fructose-1,6-bisphosphate aldolase of Neisseria meningitidis: surface localization and role in host cell adhesion. Mol Microbiol 76:605-615

51. Shams F, Oldfield NJ, Lai SK, Tunio SA, Wooldridge KG, Turner DP (2016) Fructose-1,6-bisphosphate aldolase of Neisseria meningitidis binds human plasminogen via its C-terminal lysine residue. Microbiologyopen 5:340-350

52. Puckett S, Trujillo C, Eoh H, Marrero J, Spencer J, Jackson M, Schnappinger D, Rhee K, Ehrt S (2014) Inactivation of fructose-1,6-bisphosphate aldolase prevents optimal co-catabolism of glycolytic and gluconeogenic carbon substrates in Mycobacterium tuberculosis. PLoS Pathog 10:e1004144

53. Blume M, Nitzsche R, Sternberg U, Gerlic M, Masters SL, Gupta N, McConville MJ (2015) A Toxoplasma gondii gluconeogenic enzyme contributes to robust central carbon metabolism and is essential for replication and virulence. Cell Host Microbe 18:210-220

54. Razin S, Jacobs E (1992) Mycoplasma adhesion. J Gen Microbiol 138:407-422

55. Patti JM, Hook M (1994) Microbial adhesins recognizing extracellular matrix macromolecules. Curr Opin Cell Biol 6:752-758

56. Schwarz-Linek U, Hook M, Potts JR (2004) The molecular basis of fibronectin-mediated bacterial adherence to host cells. Mol Microbiol 52:631-641

57. McDonald JA (1988) Extracellular matrix assembly. Annu Rev Cell Biol 4:183-207

58. Giron JA, Lange M, Baseman JB (1996) Adherence, fibronectin binding, and induction of cytoskeleton reorganization in cultured human cells by Mycoplasma penetrans. Infect Immun 64:197-208

59. Dallo SF, Kannan TR, Blaylock MW, Baseman JB (2002) Elongation factor Tu and E1 beta subunit of pyruvate dehydrogenase complex act as fibronectin binding proteins in Mycoplasma pneumonia. Mol Microbiol 46:1041-1051

60. Lindgren PE, Speziale P, McGavin M, Monstein HJ, Hook M, Visai L, Kostiainen T, Bozzini S, Lindberg M (1992) Cloning and expression of two different genes from Streptococcus dysgalactiae encoding fibronectin receptors. J Biol Chem 267:1924-1931

61. Grundmeier M, Hussain M, Becker P, Heilmann C, Peters G, Sinha B (2004) Truncation of fibronectin-binding proteins in Staphylococcus aureus strain Newman leads to deficient adherence and host cell invasion due to loss of the cell wall anchor function. Infect Immun 72:7155-7163 